\title{
Design and Implementation of Teaching and Examination System for Computer Application
}

\author{
Zhang Yan \\ Jiangxi Technical College of Manufacturing
}

\begin{abstract}
Abstrac-With the arrival of information era, modern society has to rapidly spread and take advantage of a dazzling array of information resources and the knowledge update cycle is becoming shorter. Therefore a teaching system is desperately needed to full play education resources, maximize resources sharing, create ideal teaching environment, make up for the demerits of traditional teaching, improve education quality, and cultivate innovative talents with innovative spirit, practical ability and can be adapted to information era. This paper firstly carries out demand analysis in the premise of clearing the system design principle and then designs system structure, main function module and systematic database.
\end{abstract}

KeyWords-Teaching System; Examination System; Computer Application; System Development

\section{INTRODUCTION}

Mastering the basic knowledge of computer application should be one of the capacities modern university students should be equipped with. Therefore, national and provincial computer rank examinations take basic knowledge of computer application as main contents. However, with the development of network and informationization, the requirement on the communication speed as well as range is expanded. Therefore, a teaching system is desperately needed to full play education resources, maximize resources sharing, create ideal teaching environment, make up for the demerits of traditional teaching, improve education quality, and cultivate innovative talents with innovative spirit, practical ability and can be adapted to information era.

In addition, various colleges and universities have to know how students master the basic knowledge of computer application. In order to accomplish this goal, almost all schools adopt examination to verify it, which can effectively evaluate the knowledge as well as skill level of students, and the grade can be deemed as an effective measuring instrument. This paper researches on the design and implementation of teaching and examination system for computer application which can effectively adopt the combination of network and multimedia to assist students thoroughly understand relevant knowledge points of computer application's teaching system to guide students take the initiative to learn and ponder so as to continually improve learning efficiency based on audio, video, and text etc. Therefore, it is essential to establish an examination system which is applicable to computer application.

\section{RESEARCH SITUATION OF COMPUTER \\ APPLICATION’S EXAMINATION SYSTEM}

With the rapid development of Internet and the popularization of computer application knowledge, the application range of computer application's teaching system is expanded. At home, some researchers begin to carry out experiment and study on the computer teaching system, which is an effective inventive support system for modern teaching with strong development momentum. At the same time, Action Plan for Invigorating 21st Century Education prepared by Ministry of Education and approved by the State Department also clears its attitude that modern distance education system is a new teaching means, which may become an important one for people to study. Therefore, the construction of teaching system based on computer application is urgent and necessary.

The online test system based on internet has been vigorously developed which will gradually replace traditional classroom examination mode and single machine examination mode. Especially in foreign 
countries, various authoritative examinations adopt online test mode such as TOEFL and Network Engineer etc.

At present, the implementation technique for various computer application examination systems adopts traditional client-server, namely $\mathrm{C} / \mathrm{S}$ design pattern. That is to say, examination contents are put on the distant server while the examination machine is equipped with application program. Then, before every examination, teachers have to install the program which is heavy work. What's more, the safety of examination procedure cannot be guaranteed.

\section{CRITICAL TECHNOLOGY FOR S YSTEM REALIZATION}

Microsoft.Net is defined as next-generation business platform. In fact, .NET structure comprehensively integrates product, service and concept to carry out deployment based on the technical infrastructure and software provided by network service. The core idea of .NET is software, that is to say, .NET as a software product with service should integrate with business, contents, information service so as to make it convenient or people to subscribe. People design, implement, operate, integrate and use the software with the assistance of network

.NET structure extracts essence of Microsoft component's object model and organically combines with the essence of loosely coupled computing to generate strong and effective Web component system to simplify pipeline operation for programmer which can enforce security. In addition, it introduces the operation system based on internet which can obviously improve the scalability and reliability of application program. The development of teaching and examination system for computer application adopts popular .NET multi-layer application structure, this standard system structure and its supportive development language shall make it convenient for users to open and integrate application, greatly shortening the development disposal time. The development tool adopts VisualStudio.NET, which can rapidly realize application platform. Fig .1 is the schematic drawing for Microsoft .NET multi-layer application structure.

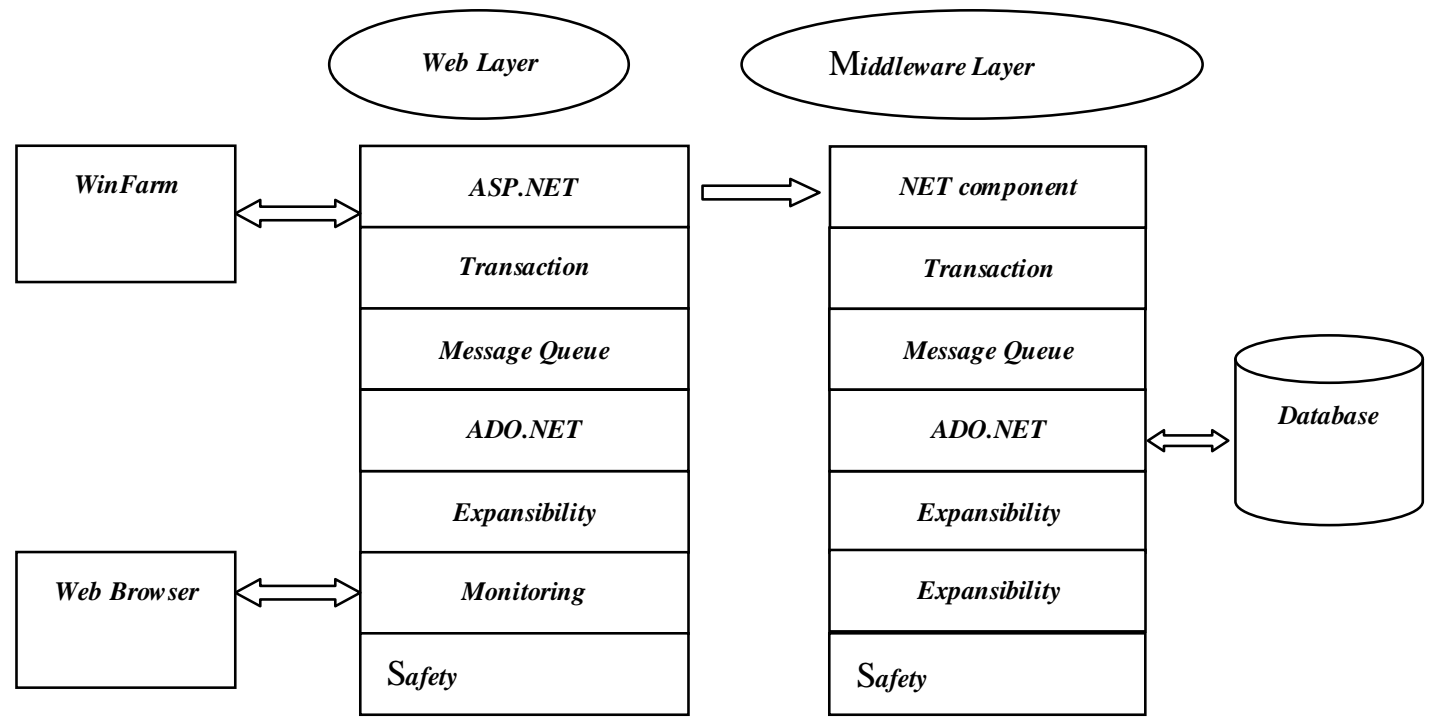

Figure 1. Schematic drawing for Microsoft .NET multi-layer application structure 


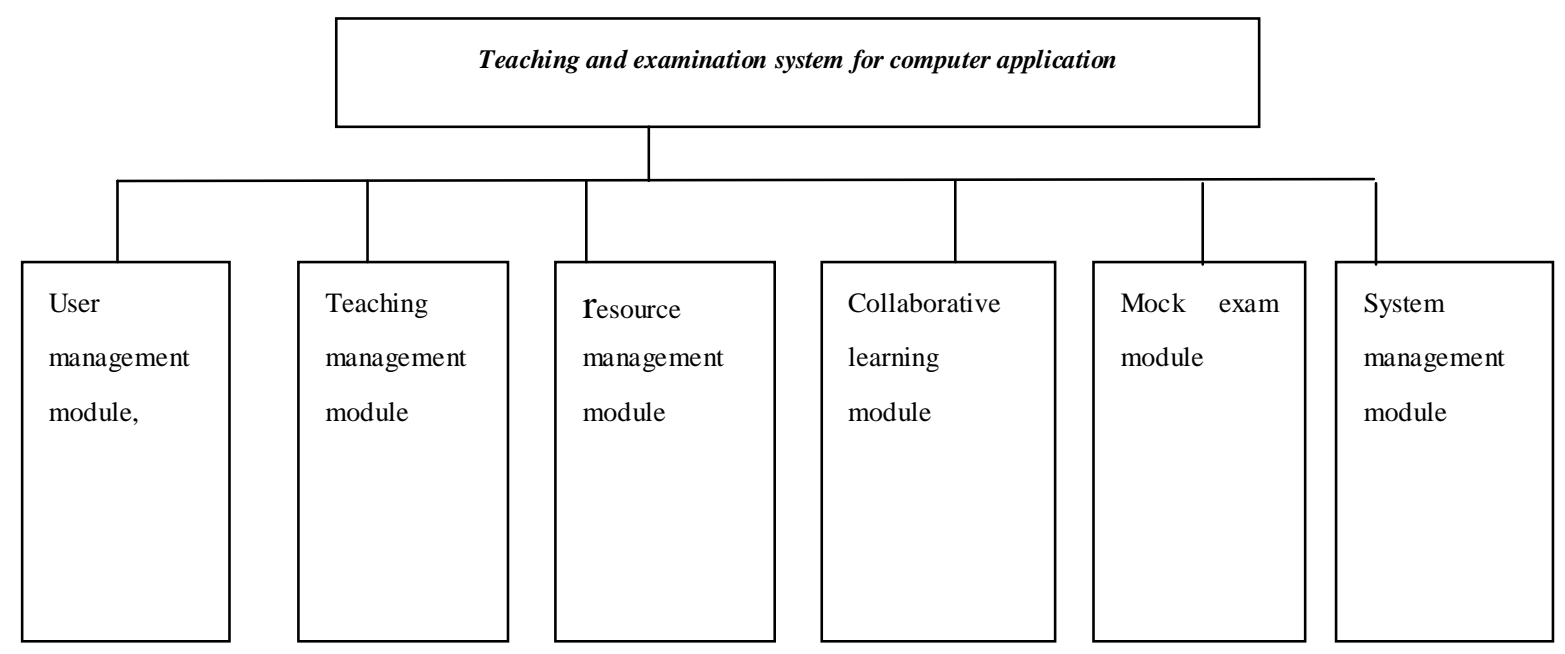

Figure 2. Computer application base function module chart of the teaching and examination system

Teaching and Examination System Design for Computer Application

This system has six functional modules: user management module, teaching management module, resource management module, collaborative learning module, mock exam module and system management module showing in Fig .2.

Fig .2 Functional modules for teaching and examination system for computer application
User registration include: demonstrate form and relevant requirements for registration; check the legitimacy for the information input by users; give friendly hint in case of mistakes; check duplication of user name; store correct information in the database; give information for those who successfully register. Fig. 3 shows the data flow for registration 


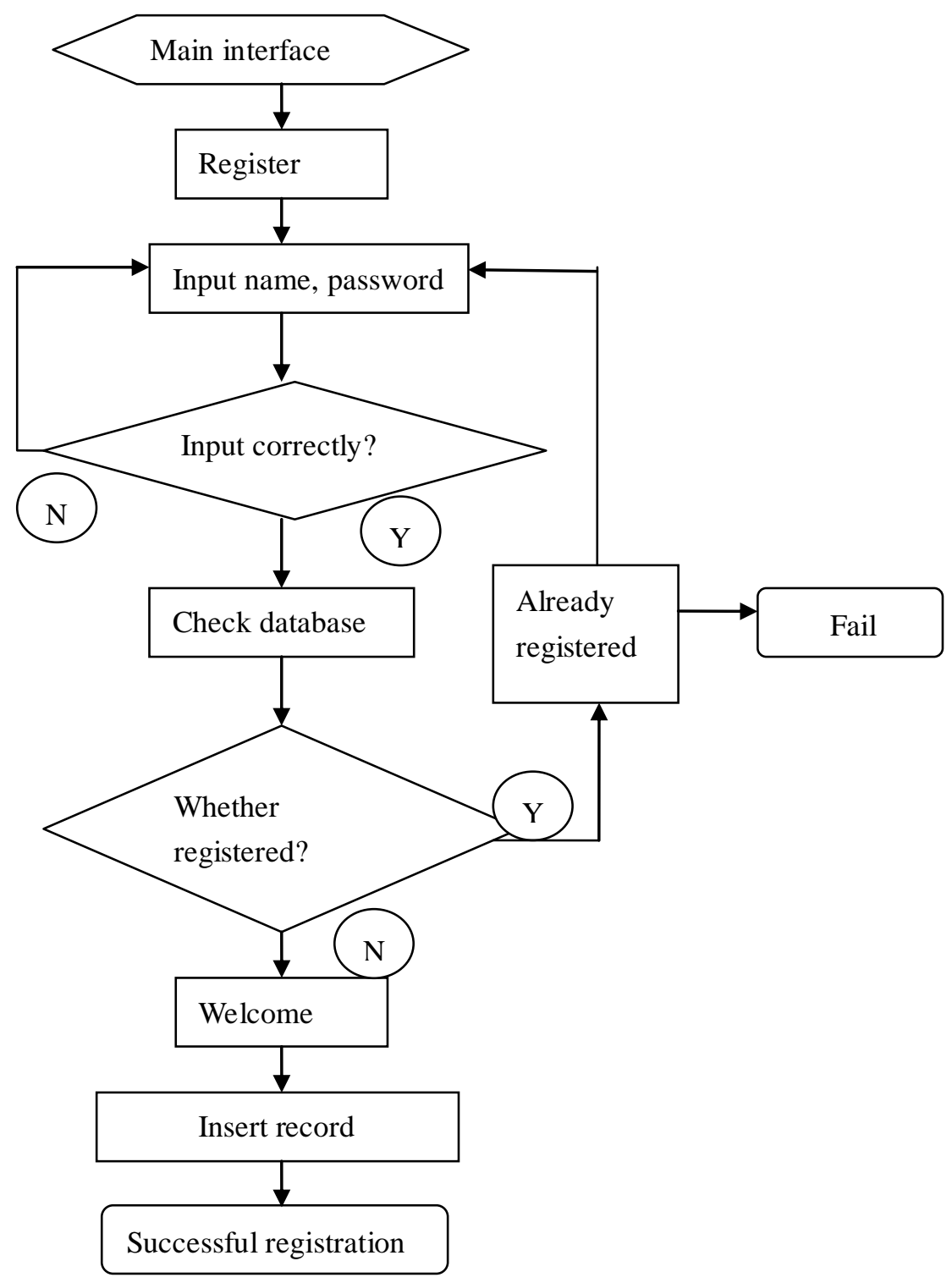

Figure 3. Data flow for student registration

\section{CONCLUSION}

This paper tries to find out the realization approaches for the teaching and exam system modules for computer application. The application adopted in this paper makes computer application teaching more convenient and effective which is in accordance with the development requirement of multimedia teaching and is an important topic of teaching reform. The researches contents in this paper show as follows:

It firstly clears the design principle, analyzes the current computer application teaching and its existing problems. Then, it introduces the demand of teaching and exam system for computer application of Hulunbeir Industrial School.
Afterwards, this paper focuses on the platform structure, functional module and database design of this system. With the assistance of .NET environment, this paper analyzes the realization of Client-Server processing program so as to study the realization of main functions and discuss on the realization of resource sharing mechanism.

Finally, this paper analyzes the security testing of Hulunbeir Industrial School's teaching and examination system for computer application and proves its effectiveness.

\section{REFERENCES}

[1] Macdonald, I. D. "A computer application to finite p-groups." Journal of the Australian Mathematical Society 17.1(1974):102-112. 
[2] Shi, Jiaoying, and Z. Pan. "China: computer graphics is fastest developing computer application." Acm Siggraph Computer Graphics (1996):11-14.

[3] Kressig, Reto W, and K. V. Echt. "Exercise Prescribing: Computer Application in Older Adults." Gerontologist 42.2(2002):273-277.

[4] Pniewski J, Sagan A, Szoplik T. Contrast control for grey-level deformation removal in images: an algorithm and a computer application[J]. Computers \& Geosciences, 2003, 29(10):1241-1247.

[5] Vinoski S. It's just a mapping problem [computer application adaptation][J]. IEEE Internet Computing, 2003, 7(3):88-90.

[6] Liu, Guoyang, and W. Chen. "Computer Application in Chemical Engineering." Guangdong Chemical Industry (2012).

[7] Wang, Xiao Dong. "EMC Technology of Reinforcement Computer Application." Electronics Process Technology (2009).
[8] Zhang J H, Yang H J. Computer Application in The Research of Green Chemistry[J]. Heibei Chemical Engineering \& Industry, 2001.

[9] Smith, C. E., A. C. Roth, and S. M. Milner. "Palm-Top Computer Application for Fluid Resuscitation in Burns: 269.." Journal of Burn Care \& Research 22(2001).

[10] Card S K, Henderson D A. CATALOGUES: A METAPHOR FOR COMPUTER APPLICATION DELIVERY[J]. Human-computer Interaction-interact, 1987:959-964.

[11] Neumann, D. (1986). A psychotherapeutic computer application: modification of technological competence. Behavior Research Methods, 18(2), 135-140.

[12] Kennedy, T., and A. G. Hoffmann. "On-Line Digital Computer Application Techniques for Complex Electric System Dispatch." Power Apparatus \& Systems IEEE Transactions on pas-87.1(1968):67 - 73. 